\title{
Performance Evaluation of a Communication Network with Dynamic Bandwidth Allocation and Bulk Arrivals
}

\author{
P.Srinivasa Rao \\ Dept. of CS \& SE, AUCE \\ ANDHRA UNIVERSITY \\ Visakhapatnam, INDIA
}

\author{
Kuda Nageswara Rao \\ Dept. of CS \& SE, AUCE \\ ANDHRA UNIVERSITY \\ Visakhapatnam, INDIA
}

\author{
K.Srinivas Rao \\ Dept. of Statistics \\ ANDHRA UNIVERSITY \\ Visakhapatnam, INDIA
}

\begin{abstract}
Communication networks had a separate deployment for each emerging service like Telephone networks, data networks and multimedia networks. In Integrated Services Network the packets are transmitted using efficient statistical multiplexing. In this paper, we develop and analyze a two-node communication network with dynamic bandwidth allocation having bulk arrivals. The performance of the statistical multiplexing is measured by approximating the arrival and the service process with Poisson process and the bulk size is uniform which is chosen such that several of the statistical characteristics of the communication network identically match with the Poisson process. Through mathematical modeling, the performance measures of the communication network like the joint probability generating function of the buffer size distribution, the average content of the buffers, the mean delays in transmission, the throughput of the nodes and utilization are derived explicitly under transient conditions. Through numerical studies, the sensitivity of the input parameters on the performance measures is also carried. It is observed that the dynamic bandwidth allocation strategy and bulk size distribution of the arrivals have significant effect on the performance measures. This network is much useful in satellite communications and Internet service providing, etc,
\end{abstract}

\section{Keywords}

Communication networks, Dynamic bandwidth allocation, Bulk arrivals, Performance measures

\section{INTRODUCTION}

Much work has been reported regarding communication networks and their performance evaluation. Martin Reiser (1982) and Jaime Jungok Bae(1991) have reviewed the communication networks and analytical methods for their evaluation. Several authors developed various communication network models with several considerations in order to analyze the situation close to the reality. One of the important considerations in communication network model is transporting data/voice more effectively with a guaranteed Quality of Service (QoS). For efficient communication, different service models have been proposed a scalable traffic management mechanism to ensure QoS. However, in some situations at broadband integrated services, the digital network has a synchronized transmission mode. The output of one transmitter is usually the input of another transmitter.

Due to the unpredicted nature of the transmission lines, congestion occurs in communication systems. In order to analyze the communication network efficiently, one has to consider the analogy between communication networks and waiting line models. Generally, the analysis in a communication system is mainly concerned with the problem of allocation and distribution of data or voice packetization, statistical multiplexing, flow control, bit dropping, link assignment, delay and routing etc. For efficient utilization of the resources, mathematical modeling provides the basic frame work in communication networks. The communication networks are modeled as interconnected queues by viewing the message as the customer, communication buffer as waiting line and all activities necessary for transmission of the message as service. This representation is the most natural with respect to the actual operation of such systems. This leads a communication network to view as a tandem or serial queuing network. Several authors have studied the communication networks as tandem queues (Kleinrock L. 1976; Yukuo hayshida, 1993; Paul Dupis et $\mathrm{al}, 2007)$.

Because of the unpredicted nature of demand at transmission lines congestion occurs in communication systems. Statistical multiplexing is one of the major considerations for efficient utilization of the resources. With the statistical multiplexing load dependent communication network models have been generated to accommodate the bit dropping methodologies (Kin K. Leung, 2002). Bit dropping method can be classified as IBD (Input Bit Dropping) and OBD (Output Bit Dropping). Depending on the implementation of the actual algorithms, IBD or OBD performance is measured. As a result of the bit dropping or flow control strategies voice quality is expected to degrade gracefully when overload occurs. The extent of degradation of service quality is a function of the fraction of voice calls lost, which in turn depends on the load. To have an efficient transmission with high quality, it is needed to consider the variation on transmission rates based on the contents of the buffers. This is often referred as dynamic bandwidth allocation.

Some algorithms have been developed with various protocols and allocation strategies for optimal utilization of bandwidth (Emre and Ezhan, 2008; Gundale and Yardi, 2008; Hongwang and Yufan, 2009; Fen Zhou et al. 2009; Stanislav, 2009). These strategies are developed based on arrival process of the packets through bit dropping and flow control techniques. It is needed to utilize the bandwidth maximum possible by developing strategies of transmission control based on buffer size. One such strategy is dynamic bandwidth allocation. In dynamic bandwidth allocation, the transmission rate of the packet is adjusted instantaneously depending upon the content of the buffer. Recently P.Suresh Varma et al (2007) has developed some communication network models using dynamic bandwidth allocation. However, they considered that the arrivals of packets to the buffer are single. But, in store-and-forward communication the messages are packetized and transmitted. When a message is packetized, the number of packets of that message is random having bulk in size. Hence, considering single packet arrival to the initial node may not accurately evaluate the performance of the communication network. Therefore, in this paper, a communication network with dynamic bandwidth allocation having bulk arrivals is developed 
and analyzed under Markovian environment. This model wick characterize the two node communication networks arising at places like Telecommunications, Satellite communications, computer communications etc. more close to the realistic situation.

The statistical multiplexing of the communication network is characterized by considering that the arrival and transmission process follow Poisson and the number of arrivals to the initial node is in batch with a random size having uniform distribution The performance of the communication network is carried through deriving the joint probability generating function of the buffer size distribution, the mean content of the buffers, the mean delay in transmission, the throughput etc. A numerical illustration for sensitivity of the network with respect to the input parameters is given.

\section{A COMMUNICATION NETWORK WITH DYANMIC BANDWIDTH ALLOCATION AND BULK ARRIVALS}

Tandem communication systems received lot of attention in literature. These communication networks consisting of two nodes, having two buffers transmits data over a common shared system. In these communication systems, the messages are packetized at the source and stored in buffers for transmission. When a message arrives, it is converted into data/voice packets of a pre-fixed length The number of packets that a message can be converted is random depending upon the length of the message. Hence, the arrivals of packets to the initial buffer is in bulk having a variable size. After being transmitted in the first node, it is transmitted through second node. In both the nodes the transmission is carried with dynamic bandwidth allocation strategy. In DBA, the transmission rate is a linear function of number of packets in the buffer. Here, it is assumed that the arrival of packets follow a compound Poisson process with arrival rate $\lambda \mathrm{E}(\mathrm{X})$, where $\mathrm{X}$ is the number of packets a message can be converted and having probability mass function as " $\mathrm{C}_{\mathrm{k}}$ " $\left\{\mathrm{C}_{\mathrm{k}}, \mathrm{k}=1,2,3, \ldots \ldots,\right\}$. The number of transmissions at each node also follow Poisson with parameters " $\mu_{1}$ " and " $\mu_{2}$ " depending upon the number of packets in first and second buffers respectively. The queue discipline is First-in-First-Out (FIFO). Let $n_{1}$ and $n_{2}$ are the random variable which denotes the number of packets in first and second buffers of the network respectively. $P_{n_{1}, n_{2}}(t)$ be the probability that there are $\mathrm{n}_{1}$ and $\mathrm{n}_{2}$ packets in first buffer and second buffer respectively. The schematic diagram representing a communication network model with bulk arrival under equilibrium is shown in figure 1.

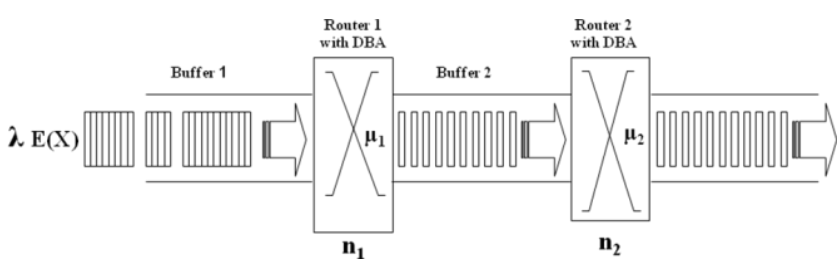

Figure 1. Communication network with dynamic bandwidth allocation and bulk arrivals

Let $\mathrm{P}_{\mathrm{n}_{1}, \mathrm{n}_{2}}(\mathrm{t})$ be the probability that there are $\mathrm{n} 1$ packets in the first buffer and $\mathrm{n} 2$ packets in the second buffer at time $\mathrm{t}$. The difference - differential equations of the Communication network are

$$
\begin{aligned}
& \frac{\partial P_{n_{1}, n_{2}}(t)}{\partial t}=-\lambda+n_{1} \mu_{1}+n_{2} \mu_{2} P_{n_{1}, n_{2}}(t)+n_{1}+1 \mu_{1} P_{n_{1}+, n_{2}-1}(t)+n_{2}+1 \mu_{2} P_{n_{1}, n_{2}+1}(t)+\lambda\left[\sum_{k=1}^{n_{1}} P_{n_{1}-k, n_{2}} t C_{k}\right] \\
& \frac{\partial \mathbf{P}_{n_{1}, 0}(t)}{\partial t}=-\lambda+n_{1} \mu_{1} \quad P_{n_{1}, 0}(t)+\mu_{2} P_{n_{1}, 1}(t)+\lambda \sum_{k=1}^{n_{1}} P_{n_{1}-k, 0} \quad t \quad C_{k} \\
& \frac{\partial P_{0, n_{2}}(t)}{\partial t}=-\lambda+n_{2} \mu_{2} \quad P_{0, n_{2}}(t)+\mu_{1} P_{1, n_{2}-1}(t)+\left(n_{2}+1\right) \mu_{2} P_{0, n_{2}+1}(t) \\
& \frac{\partial \mathbf{P}_{0,0}(t)}{\partial \mathbf{t}}=-\lambda \mathbf{P}_{\mathrm{O}, \mathrm{O}}(\mathbf{t})+\mu_{2} \mathbf{P}_{\mathrm{O}, 1} \quad \mathbf{t} \\
& \frac{\partial \mathbf{P}_{1, \mathrm{o}}(\mathbf{t})}{\partial \mathbf{t}}=-\lambda \mu_{1} \mathbf{P}_{1, \mathrm{o}} \quad \mathbf{t}+\mu_{2} \mathbf{P}_{1,1} \quad \mathbf{t}+\lambda \mathbf{P}_{\mathrm{o}, \mathrm{o}} \quad \mathbf{t} \quad \mathbf{C}_{1} \\
& \frac{\partial \mathbf{P}_{0,1}(t)}{\partial t}=-\lambda+\mu_{2} \quad \mathbf{P}_{0,1}(t)+\mu_{1} \mathbf{P}_{1,0}(t)+2 \mu_{2} \mathbf{P}_{0,2}(t)
\end{aligned}
$$

with initial conditions

$$
\mathrm{P}_{00}(0)=1 ; \mathrm{P}_{\mathrm{n}_{1}, \mathrm{n}_{2}}(0)=0 \text { for } \mathrm{n}_{1}, \mathrm{n}_{2}>0
$$

Let $\mathrm{P}\left(\mathrm{z}_{1}, \mathrm{z}_{2} ; \mathrm{t}\right)$ be the joint probability generating function of $\mathrm{P}_{\mathrm{n}_{1}, \mathrm{n}_{2}}(\mathrm{t})$ then

$$
\mathbf{P}\left(\mathrm{z}_{1}, \mathbf{z}_{2} ; \mathrm{t}\right)=\sum_{\mathrm{n}_{1}=0}^{\infty} \sum_{\mathrm{n}_{2}=0}^{\infty} \mathbf{Z}_{1}^{\mathrm{n}_{1}} \mathbf{Z}_{2}^{\mathrm{n}_{2}} \mathbf{P}_{\mathrm{n}_{1}, \mathrm{n}_{2}}(\mathrm{t})
$$

multiplying the equations (1) to (6) with corresponding $\mathrm{Z}_{1}^{\mathrm{n}_{1}}, \mathrm{Z}_{2}^{\mathrm{n}_{2}}$ and summing oerall $\mathrm{n}_{1}=0,1,2,3, \ldots$ and $\mathrm{n}_{2}=0,1,2,3, \ldots$ one can get

$$
\begin{aligned}
\sum_{n_{1}=1}^{\infty} \sum_{n_{2}=1}^{\infty} \frac{\partial}{\partial t} P_{n_{1}, n_{2}}(t) Z_{1}^{n_{1}} Z_{2}^{n_{2}} & =-\left[\sum_{n_{1}=}^{\infty} \sum_{n_{2}=1}^{\infty} \lambda+n_{1} \mu_{1}+n_{2} \mu_{2} P_{n_{1}, n_{2}}(t) \cdot Z_{1}^{n_{1}} Z_{2}^{n_{2}}\right] \\
& +\sum_{n_{1}=1}^{\infty} \sum_{n_{2}}^{\infty}\left(n_{1}+1\right) \mu_{1} P_{n_{1}+1, n_{2}-1}(t) \cdot Z_{1}^{n_{1}} Z_{2}^{n_{2}} \\
& +\sum_{n_{1}=1}^{\infty} \sum_{n_{2}}^{\infty}\left(n_{2}+1\right) \mu_{2} P_{n_{1}, n_{2}+1}(t) \cdot Z_{1}^{n_{1}} Z_{2}^{n_{2}} \\
& +\sum_{n_{1}=1}^{\infty} \sum_{n_{2}}^{\infty}\left[\lambda \sum_{k=1}^{n_{1}} P_{n_{1}-k, n_{2}}(t) \cdot C_{k}\right] Z_{1}^{n_{1}} Z_{2}^{n_{2}}
\end{aligned}
$$

After simplification,

$\frac{\partial \mathrm{P}\left(\mathrm{Z}_{1} \mathrm{Z}_{2} ; \mathrm{t}\right)}{\partial \mathrm{t}}=\left[\lambda\left(\mathrm{c} \mathrm{Z}_{1}-1\right)\right] \mathrm{P}\left(\mathrm{Z}_{1}, \mathrm{Z}_{2} ; \mathrm{t}\right)+\mu_{1}\left(\mathrm{Z}_{2}-\mathrm{Z}_{1}\right) \cdot \frac{\partial \mathrm{P}\left(\mathrm{Z}_{1} \mathrm{Z}_{2} ; \mathrm{t}\right)}{\partial \mathrm{Z}_{1}}+\mu_{2}\left(1-\mathrm{Z}_{2}\right) \cdot \frac{\partial \mathrm{P}\left(\mathrm{Z}_{1} \mathrm{Z}_{2} ; \mathrm{t}\right)}{\partial \mathrm{Z}_{2}}$

Rearrange the terms

$\frac{\partial \mathrm{P}\left(\mathrm{Z}_{1} \mathbf{Z}_{2} ; \mathrm{t}\right)}{\partial \mathrm{t}}-\mu_{1}\left(\mathrm{Z}_{2}-\mathrm{Z}_{1}\right) \cdot \frac{\partial \mathrm{P}\left(\mathrm{Z}_{1} \mathbf{Z}_{2} ; \mathrm{t}\right)}{\partial \mathbf{Z}_{1}}-\mu_{2}\left(1-\mathrm{Z}_{2}\right) \cdot \frac{\partial \mathrm{P}\left(\mathrm{Z}_{1} \mathbf{Z}_{2} ; \mathrm{t}\right)}{\partial \mathrm{Z}_{2}}=\left[\lambda\left(\mathrm{c} \mathbf{Z}_{1}-1\right)\right] \mathrm{P}\left(\mathrm{Z}_{1}, \mathrm{Z}_{2} ; \mathrm{t}\right)$

Using the Lagrangian's method, the auxiliary equations of the equation (9) are

$\frac{\partial \mathrm{t}}{1}=\frac{-\partial \mathrm{Z}_{1}}{\mu_{1}\left(\mathrm{Z}_{2}-\mathrm{Z}_{1}\right)}=\frac{-\partial \mathrm{Z}_{2}}{\mu_{2}\left(1-\mathrm{Z}_{2}\right)}=\frac{\partial \mathrm{P}\left(\mathrm{Z}_{1} \mathrm{Z}_{2} ; \mathrm{t}\right)}{\lambda\left(\mathrm{c}\left(\mathrm{Z}_{1}\right)-1\right) \mathrm{P}\left(\mathrm{Z}_{1}, \mathrm{Z}_{2} ; \mathrm{t}\right)}$

Solving the equation (10) which has the solution with initial conditions

$$
\begin{aligned}
& \mathbf{P}_{\mathrm{OO}}(\mathrm{O})=1 ; \mathrm{P}_{\mathrm{n}_{1}, \mathrm{n}_{2}}(\mathrm{O})=\mathrm{O} \text { for all } \mathrm{n}_{1}, \mathrm{n}_{2}>0 \\
& \mathbf{u}=\left(\mathbf{Z}_{2}-\mathbf{1}\right) \mathrm{e}^{-\mu_{2} \mathrm{t}} \\
& \mathbf{v}=\left[\left(\mathrm{Z}_{1}-1\right)+\frac{\mu_{1}}{\mu_{2}-\mu_{1}}\left(Z_{2}-1\right)\right] \mathrm{e}^{-\mu_{1} \mathrm{t}} \\
& \mathrm{w}=\operatorname{P} \cdot \exp \left[-\lambda \sum_{\mathrm{k}=1}^{\infty} \sum_{\mathrm{r}=1}^{\mathrm{k}} \sum_{\mathrm{J}=0}^{\mathrm{r}}-1^{2 \mathrm{r}-\mathrm{J}} \mathrm{C}_{\mathrm{k}}\left({ }^{\mathrm{k}} \mathrm{C}_{\mathrm{r}}\right)\left({ }^{\mathrm{r}} \mathrm{C}_{\mathrm{J}}\right)\left(\frac{\mathrm{u} \mu_{1}}{\mu_{2}-\mu_{1}}\right)^{\mathrm{J}} \mathrm{v}^{\mathrm{r}-\mathrm{J}} \frac{\mathrm{e}^{\mathrm{J} \mu_{2}+(\mathrm{r}-\mathrm{J}) \mu_{1} \mathrm{t}}}{\mathrm{J}_{\mu_{2}}+(\mathrm{r}-\mathrm{J}) \mu_{1}}\right]
\end{aligned}
$$

Where $\mathrm{u}, \mathrm{v}$ and $\mathrm{w}$ are arbitrary integral constants. Therefore $P=w \cdot \exp \left[\lambda \sum_{k=1}^{\infty} \sum_{r=1}^{k} \sum_{J=0}^{r}-1{ }^{2 r-J} C_{k}\left({ }^{k} C_{r}\right)\left({ }^{r} C_{J}\right)\left(\frac{u \mu_{1}}{\mu_{2}-\mu_{1}}\right)^{J} v^{r-J} \frac{e^{J \mu_{2}+(r-J) \mu_{1} t}}{J \mu_{2}+(r-J) \mu_{1}}\right]$

Substituting the value of ' $\mathrm{w}$ '

$$
\begin{array}{r}
P=\left(\exp \left[\lambda \sum_{\mathrm{k}=1}^{\infty} \sum_{\mathrm{r}=1}^{\mathrm{k}} \sum_{\mathrm{J}=0}^{\mathrm{r}}-1^{2 \mathrm{r}-\mathrm{J}} \mathrm{C}_{\mathrm{k}}\left({ }^{\mathrm{k}} \mathrm{C}_{\mathrm{r}}\right)\left({ }^{\mathrm{r}} \mathrm{C}_{\mathrm{J}}\right)\left(\frac{\mathrm{u} \mu_{1}}{\mu_{2}-\mu_{1}}\right)^{\mathrm{J}} \mathrm{v}^{\mathrm{r}-\mathrm{J}} \frac{1}{\mathrm{~J} \mu_{2}+(\mathrm{r}-\mathrm{J}) \mu_{1}}\right]\right) . \\
\left(\exp \left[\lambda \sum_{\mathrm{k}=1}^{\infty} \sum_{\mathrm{r}=1}^{\mathrm{k}} \sum_{\mathrm{J}=0}^{\mathrm{r}}-1^{2 \mathrm{r}-\mathrm{J}} \mathrm{C}_{\mathrm{k}}\left({ }^{\mathrm{k}} \mathrm{C}_{\mathrm{r}}\right)\left({ }^{\mathrm{r}} \mathrm{C}_{\mathrm{J}}\right)\left(\frac{\mathrm{u} \mu_{1}}{\mu_{2}-\mu_{1}}\right)^{\mathrm{J}} \mathrm{v}^{\mathrm{r}-\mathrm{J}} \frac{\mathrm{e}^{\mathrm{J} \mu_{2}+(\mathrm{r}-\mathrm{J}) \mu_{1} \mathrm{t}}}{\mathrm{J} \mu_{2}+(\mathrm{r}-\mathrm{J}) \mu_{1}}\right]\right)
\end{array}
$$


This implies

$\mathrm{P}=\exp \left[\lambda \sum_{\mathrm{k}=1}^{\infty} \sum_{\mathrm{r}=1}^{\mathrm{k}} \sum_{\mathrm{J}=0}^{\mathrm{r}}-1{ }^{2 \mathrm{r}-\mathrm{J}} \mathrm{C}_{\mathrm{k}}\left({ }^{\mathrm{k}} \mathrm{C}_{\mathrm{r}}\right)\left({ }^{\mathrm{r}} \mathrm{C}_{\mathrm{J}}\right)\left(\frac{\mathrm{u} \mu_{1}}{\mu_{2}-\mu_{1}}\right)^{\mathrm{J}} \mathrm{v}^{\mathrm{r}-\mathrm{J}} \frac{\mathrm{e}^{\mathrm{J}_{\mu_{2}+(\mathrm{r}-\mathrm{J}) \mu_{1} \mathrm{t}}-1}}{\mathrm{~J}_{\mu_{2}}+(\mathrm{r}-\mathrm{J}) \mu_{1}}\right]$

Substituting the values of $\mathrm{u}$ and $\mathrm{v}$ in the above equation and simplifying, one can get the joint probability generating function of the two node communication network with bulk arrivals as

$\mathrm{P}\left(\mathrm{Z}_{1}, \mathrm{Z}_{2}, \mathrm{t}\right)=\exp \left[\lambda \sum_{\mathrm{k}=1}^{\infty} \sum_{\mathrm{r}=1}^{\mathrm{k}=1=0} \sum^{\mathrm{r}}-1{ }^{2 \mathrm{r}-\mathrm{J}} \mathrm{C}_{\mathrm{k}}\left({ }^{\mathrm{k}} \mathrm{C}_{\mathrm{r}}\right)\left({ }^{\mathrm{r}} \mathrm{C}_{\mathrm{J}}\right)\left(\frac{\mu_{1}\left(\mathrm{Z}_{2}-1\right)}{\mu_{2}-\mu_{1}}\right)^{\mathrm{J}}\left(\left(\mathrm{Z}_{1}-1\right)+\frac{\mu_{1}\left(\mathrm{Z}_{2}-1\right)}{\mu_{2}-\mu_{1}}\right)^{\mathrm{r}-\mathrm{J}} \frac{1-\mathrm{e}^{\mathrm{J} \mathrm{K}_{2}+(\mathrm{r}-\mathrm{J}) \mu_{1} \mathrm{t}}}{\mathrm{J} \mu_{2}+(\mathrm{r}-\mathrm{J}) \mu_{1}}\right]$

\section{PERFORMANCE MEASURES OF THE NETWORK}

The probability that the network is empty is

$\mathrm{P}_{00}(\mathrm{t})=\exp \left[\lambda \sum_{\mathrm{k}=1}^{\infty} \sum_{\mathrm{r}=1}^{\mathrm{k}} \sum_{\mathrm{J}=0}^{\mathrm{r}}-1{ }^{2 \mathrm{r}} \mathrm{C}_{\mathrm{k}}\left({ }^{\mathrm{k}} \mathrm{C}_{\mathrm{r}}\right)\left({ }^{\mathrm{r}} \mathrm{C}_{\mathrm{J}}\right) \mu_{1}{ }^{\mathrm{J}} \frac{-\mu_{2}{ }^{\mathrm{r}-\mathrm{J}}}{\mu_{2}-\mu_{1}{ }^{\mathrm{r}}} \frac{1-\mathrm{e}^{-\mathrm{J} \mu_{2}+(\mathrm{r}-\mathrm{J}) \mu_{\mathrm{H}} \mathrm{t}}}{\mathrm{J} \mu_{2}+(\mathrm{r}-\mathrm{J}) \mu_{1}}\right]$

The probability generating function of the first buffer size distribution is

$\mathbf{P}\left(\mathrm{Z}_{1}, \mathrm{t}\right)=\exp \left[\lambda \sum_{\mathrm{k}=1}^{\infty} \sum_{\mathrm{r}=1}^{\mathrm{k}} \mathrm{C}_{\mathrm{k}}{ }^{\mathrm{k}} \mathrm{C}_{\mathrm{r}} \mathrm{Z}_{1}-1{ }^{3 \mathrm{r}} \frac{1-\mathrm{e}^{-\mathrm{r} \mu_{1} \mathrm{t}}}{\mathrm{r} \mu_{1}}\right]$

The probability that the first buffer is empty is

$\mathbf{P}_{0 .}(t)=\exp \left[\lambda \sum_{\mathrm{k}=1}^{\infty} \sum_{\mathrm{r}=1}^{\mathrm{k}} \mathrm{C}_{\mathrm{k}}{ }^{\mathrm{k}} \mathrm{C}_{\mathrm{r}}-1{ }^{3 \mathrm{r}} \frac{1-\mathrm{e}^{-\mathrm{r} \mu_{1} \mathrm{t}}}{\mathrm{r} \mu_{1}}\right]$

The mean number of packets in the first buffer is

$\mathbf{L}_{1}=\frac{\lambda}{\mu_{1}}\left[\sum_{\mathrm{k}=1}^{\infty} \mathbf{C}_{\mathrm{k}} \cdot \mathbf{k} 1-\mathrm{e}^{-\mu_{1} \mathrm{t}}\right]$

The utilization of the first node is

$\mathbf{U}_{1}=1-\exp \left[\lambda \sum_{\mathrm{k}=1}^{\infty} \sum_{\mathrm{r}=1}^{\mathrm{k}} \mathrm{C}_{\mathrm{k}}{ }^{\mathrm{k}} \mathrm{C}_{\mathrm{r}}-1{ }^{3 \mathrm{r}} \frac{1-\mathrm{e}^{-\mathrm{r} \mu_{1} \mathrm{t}}}{\mathrm{r} \mu_{1}}\right]$

The probability generating function of the second buffer size distribution is

$\mathrm{P}\left(\mathrm{Z}_{2}, \mathrm{t}\right)=\exp \left[\lambda \sum_{\mathrm{k}=1}^{\infty} \sum_{\mathrm{r}=1}^{\mathrm{k}} \sum_{\mathrm{J}=0}^{\mathrm{r}}-1{ }^{2 \mathrm{r}-\mathrm{J}} \mathrm{C}_{\mathrm{k}}\left({ }^{\mathrm{k}} \mathrm{C}_{\mathrm{r}}\right)\left({ }^{\mathrm{r}} \mathrm{C}_{\mathrm{J}}\right)\left(\frac{\mu_{1}\left(\mathrm{Z}_{2}-1\right)}{\mu_{2}-\mu_{1}}\right)^{\mathrm{r}} \frac{1-\mathrm{e}^{-\mathrm{J} \mu_{2}+(\mathrm{r}-\mathrm{J}) \mu_{1} \mathrm{t}}}{\mathrm{J} \mu_{2}+(\mathrm{r}-\mathrm{J}) \mu_{1}}\right]$

The probability that the second buffer is empty is

$\mathrm{P}_{.0}(\mathrm{t})=\exp \left[\lambda \sum_{\mathrm{k}=1}^{\infty} \sum_{\mathrm{r}=1}^{\mathrm{k}} \sum_{\mathrm{J}=0}^{\mathrm{r}}-1{ }^{3 \mathrm{r}-\mathrm{J}} \mathrm{C}_{\mathrm{k}}\left({ }^{\mathrm{k}} \mathrm{C}_{\mathrm{r}}\right)\left({ }^{\mathrm{r}} \mathrm{C}_{\mathrm{J}}\right)\left(\frac{\mu_{1}}{\mu_{2}-\mu_{1}}\right)^{\mathrm{r}} \frac{1-\mathrm{e}^{-\mathrm{J} \mu_{2}+(\mathrm{r}-\mathrm{J}) \mu_{1} \mathrm{t}}}{\mathrm{J} \mu_{2}+(\mathrm{r}-\mathrm{J}) \mu_{1}}\right]$

The mean number of packets in the second buffer is

$\mathrm{L}_{2}=\frac{\lambda}{\mu_{2}}\left[\sum_{\mathrm{k}=1}^{\infty} \mathrm{C}_{\mathrm{k}} \cdot \mathrm{k}\left[1-\mathrm{e}^{-\mu_{2} \mathrm{t}}+\frac{\mu_{2}}{\mu_{2}-\mu_{1}} \mathrm{e}^{-\mu_{2} \mathrm{t}}-\mathrm{e}^{-\mu_{1} \mathrm{t}}\right]\right]$

The utilization of the second node is

$\mathrm{U}_{2}=1-\exp \left[\lambda \sum_{\mathrm{k}=1}^{\infty} \sum_{\mathrm{r}=1}^{k} \sum_{\mathrm{J}=0}^{\mathrm{r}}-{ }^{3 r-\mathrm{J}} \mathrm{C}_{\mathrm{k}}\left({ }^{k} \mathrm{C}_{\mathrm{r}}\right)\left({ }^{\mathrm{r}} \mathrm{C}_{\mathrm{J}}\right)\left(\frac{\mu_{1}}{\mu_{2}-\mu_{1}}\right)^{\mathrm{r}} \frac{1-\mathrm{e}^{-\mathrm{J} \mu_{2}+(\mathrm{r}-\mathrm{J}) \mu_{\mu_{1} \mathrm{t}}}}{\mathrm{J} \mu_{2}+(\mathrm{r}-\mathrm{J}) \mu_{1}}\right]$

The mean number of packets in the network is

$\mathrm{L}_{\mathrm{N}}=\mathrm{L}_{1}+\mathrm{L}_{2}$

Throughput of the first node is

$\operatorname{Thp}_{1}=\mu_{1}\left[1-\exp \left[\lambda \sum_{\mathrm{k}=1}^{\infty} \sum_{\mathrm{r}=1}^{\mathrm{k}} \mathrm{C}_{\mathrm{k}}{ }^{\mathrm{k}} \mathrm{C}_{\mathrm{r}}-\mathbf{1}^{3 \mathrm{r}} \frac{1-\mathrm{e}^{-\mathrm{r} \mu_{1} \mathrm{t}}}{\mathrm{r} \mu_{1}}\right]\right]$

The average delay in the first buffer is
W $N_{1}=\frac{L_{1}}{\operatorname{Thp}_{1}}=\frac{\frac{\lambda}{\mu_{1}}\left[\sum_{k=1}^{\infty} C_{k} \cdot k 1-e^{-\mu_{1} t}\right]}{\mu_{1}\left[1-\exp \left[\lambda \sum_{k=1}^{\infty} \sum_{r=1}^{k} C_{k}{ }^{k} C_{r}-1{ }^{3 r} \frac{1-e^{-r \mu_{1} t}}{r \mu_{1}}\right]\right]}$

Throughput of the second node is

$\operatorname{Thp}_{2}=\mu_{2}\left[1-\exp \left[\lambda \sum_{\mathrm{k}=1}^{\infty} \sum_{\mathrm{r}=1}^{k} \sum_{\mathrm{J}=0}^{\mathrm{r}}-1^{3 r-\mathrm{J}} \mathrm{C}_{\mathrm{k}}\left({ }^{\mathrm{k}} \mathrm{C}_{\mathrm{r}}\right)\left(\mathrm{C}_{\mathrm{J}}\right)\left(\frac{\mu_{1}}{\mu_{2}-\mu_{1}}\right)^{\mathrm{r}} \frac{1-\mathrm{e}^{-\mathrm{J} \mu_{2}+(\mathrm{r}-\mathrm{J}) \mu_{1} \mathrm{t}}}{\mathrm{J} \mu_{2}+(\mathrm{r}-\mathrm{J}) \mu_{1}}\right]\right.$

The average delay in the second buffer is

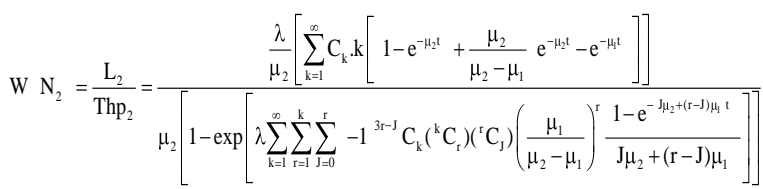

The variance of the number of packets in the first buffer is

$\operatorname{Var}\left(\mathrm{N}_{1}\right)=\lambda\left[\sum_{\mathrm{k}=1}^{\infty} \mathrm{C}_{\mathrm{k}} \mathrm{k}(\mathrm{k}-1)\left(\frac{1-\mathrm{e}^{-2 \mu_{1} \mathrm{t}}}{2 \mu_{1}}\right)+\sum_{\mathrm{k}=1}^{\infty} \mathrm{C}_{\mathrm{k}} \mathrm{k}\left(\frac{1-\mathrm{e}^{-\mu_{1} \mathrm{t}}}{\mu_{1}}\right)\right]$

The variance of number of packets in the second buffer is

$$
\begin{aligned}
\operatorname{Var}\left(\mathrm{N}_{2}\right)= & \left\{\left(\sum_{\mathrm{k}=1}^{\infty} \mathrm{C}_{\mathrm{nk}} \cdot \mathrm{k}(\mathrm{k}-1)\right)\left(\frac{\mu_{1}}{\mu_{1}-\mu_{2}}\right)^{2}\left[\left(\frac{1-\mathrm{e}^{-2 \mu_{1} \mathrm{t}}}{2 \mu_{1}}\right)-2\left(\frac{1-\mathrm{e}^{-\left(\mu_{1}+\mu_{2}\right) t}}{\mu_{1}+\mu_{2}}\right)+\left(\frac{1-\mathrm{e}^{-2 \mu_{2} \mathrm{t}}}{2 \mu_{2}}\right)\right]\right\} \\
& +\left\{\lambda \sum_{\mathrm{k}=1}^{\infty} \mathrm{k} \cdot \mathrm{C}_{\mathrm{k}}\left[\left(\frac{1-\mathrm{e}^{-\mu_{2} \mathrm{t}}}{\mu_{2}}\right)-\left(\frac{\mathrm{e}^{-\mu_{2} t}-\mathrm{e}^{-\mu_{1} \mathrm{t}}}{\mu_{1}-\mu_{2}}\right)\right]\right\}
\end{aligned}
$$

The coefficient of variation of the number of packets in the first buffer is

cv $\mathrm{N}_{1}=\frac{\sqrt{\mathrm{Var} \mathrm{N}_{1}}}{\mathbf{L}_{1}}$

The coefficient of variation of the number of packets in the second buffer is

cv $\mathrm{N}_{2}=\frac{\sqrt{\mathrm{Var} \mathrm{N}_{2}}}{\mathrm{~L}_{2}}$

\section{PARTICULAR CASE WHEN THE BATCH SIZE IS UNIFORMLY DISTRIBUTED}

For obtaining the performance of the communication network at is needed to know the functional form of the probability mass function of the number of packets that a message can be converted $\left(\mathrm{C}_{\mathrm{k}}\right)$. Let the batch size of packets follows a uniform (rectangular) distribution. Then, the probability distribution of the batch size of packets in a message is $\mathrm{C}_{\mathrm{k}}=\frac{1}{\mathrm{~b}-\mathrm{a}+1}$ for $\mathrm{k}=\mathrm{a}, \mathrm{a}+1, \ldots, \mathrm{b}$. The mean number of packets in a message is $\left(\frac{a+b}{2}\right)$ and its variance is $\frac{1}{12}\left[\mathbf{b}-\mathbf{a}+\mathbf{1}^{2}-\mathbf{1}\right]$. Substituting the value of $\mathrm{C}_{\mathrm{k}}$ in (1), we get the joint probability generating function of the number of packets in both the buffers is

$P\left(Z_{1}, Z_{2}, t\right)=\exp \left[\lambda \sum_{k=1}^{\infty} \sum_{r=1}^{k} \sum_{J=0}^{r}-1{ }^{2 r-s}\left(\frac{1}{b-a+1}\right)\left({ }^{k} C_{r}\right)\left({ }^{r} C_{J}\right)\left(\frac{\mu_{1}\left(Z_{2}-1\right)}{\mu_{2}-\mu_{1}}\right)^{J}\left(\left(Z_{1}-1\right)+\frac{\mu_{1}\left(Z_{2}-1\right)}{\mu_{2}-\mu_{1}}\right)^{r-J} \frac{1-e^{J} \mu_{2}+(t-J) \mu_{1} t}{J \mu_{2}+(r-J) \mu_{1}}\right]$

The probability that the network is empty is

$\left.\mathrm{P}_{00}(\mathrm{t})=\exp \left[\lambda \sum_{\mathrm{k}=\mathrm{a}=1}^{\mathrm{b}=1} \sum_{\mathrm{j}=0}^{\mathrm{k}} \sum^{\mathrm{r}}-1^{2 \mathrm{r}}\left(\frac{1}{\mathrm{~b}-\mathrm{a}+1}\right)\left({ }^{\mathrm{k}} \mathrm{C}_{\mathrm{r}}\right)\left({ }^{\mathrm{r}} \mathrm{C}_{\mathrm{J}}\right) \mu_{1}{ }^{\mathrm{J}} \frac{-\mu_{2}{ }^{\mathrm{r}-\mathrm{j}}}{\mu_{2}-\mu_{1}{ }^{\mathrm{r}}} \frac{1-\mathrm{e}^{\mathrm{J} \mu_{2}+(\mathrm{r}-\mathrm{J}) \mu_{1} \mathrm{t}}}{j \mu_{2}+(\mathrm{r}-\mathrm{j}) \mu_{1}}\right)\right]$

The probability generating function of the first buffer size distribution is 
$\mathrm{P}\left(\mathrm{Z}_{1}, \mathrm{t}\right)=\exp \left[\lambda \sum_{\mathrm{k}=\mathrm{a}=1}^{\mathrm{b}} \sum_{\mathrm{r}=1}^{\mathrm{k}}\left(\frac{1}{\mathrm{~b}-\mathrm{a}+1}\right){ }^{\mathrm{k}} \mathrm{C}_{\mathrm{r}} \mathrm{Z}_{1}-1^{3 \mathrm{r}} \frac{1-\mathrm{e}^{-\mathrm{r} \mu_{1} \mathrm{t}}}{\mathrm{r} \mu_{1}}\right]$

The probability that the first buffer is empty as

$\mathrm{P}_{0 .}(\mathrm{t})=\exp \left[\lambda \sum_{\mathrm{k}=\mathrm{a}}^{\mathrm{b}} \sum_{\mathrm{r}=1}^{\mathrm{k}}\left(\frac{1}{\mathrm{~b}-\mathrm{a}+1}\right){ }^{\mathrm{k}} \mathrm{C}_{\mathrm{r}}-1^{3 \mathrm{r}} \frac{1-\mathrm{e}^{-\mathrm{r} \mu_{1} \mathrm{t}}}{\mathrm{r} \mu_{1}}\right]$

The mean number of packets in the first buffer is

$\mathrm{L}_{1}=\frac{\lambda(\mathrm{a}+\mathrm{b})}{2 \mu_{1}} 1-\mathrm{e}^{-\mu_{1} \mathrm{t}}$

The utilization of the first node is

$\mathrm{U}_{1}=1-\exp \left[\lambda \sum_{\mathrm{k}=\mathrm{a}}^{\mathrm{b}} \sum_{\mathrm{r}=1}^{\mathrm{k}}\left(\frac{1}{\mathrm{~b}-\mathrm{a}+1}\right){ }^{\mathrm{k}} \mathrm{C}_{\mathrm{r}}-1^{3 \mathrm{r}} \frac{1-\mathrm{e}^{-\mathrm{r} \mu_{1} \mathrm{t}}}{\mathrm{r} \mu_{1}}\right]$

The probability generating function of the second buffer size distribution is

$P\left(Z_{2}, t\right)=\exp \left[\lambda \sum_{k=a}^{b} \sum_{r=1}^{k} \sum_{J=0}^{r}-1^{2 r-J}\left(\frac{1}{b-a+1}\right)\left({ }^{k} C_{r}\right)\left({ }^{k} C_{J}\right)\left(\frac{\mu_{1}\left(Z_{2}-1\right)}{\mu_{2}-\mu_{1}}\right)^{r} \frac{1-e^{-J \mu_{2}+(r-J) \mu_{1} t}}{J \mu_{2}+(r-J) \mu_{1}}\right]$

The probability that the second buffer is empty is

$\mathrm{P}_{.0}(\mathrm{t})=\exp \left[\lambda \sum_{\mathrm{k}=\mathrm{a}}^{\mathrm{b}} \sum_{\mathrm{r}=1}^{\mathrm{k}} \sum_{\mathrm{J}=0}^{\mathrm{r}}-\mathrm{l}^{3 \mathrm{r}-\mathrm{J}}\left(\frac{1}{\mathrm{~b}-\mathrm{a}+1}\right)\left({ }^{\mathrm{k}} \mathrm{C}_{\mathrm{r}}\right)\left({ }^{\mathrm{r}} \mathrm{C}_{\mathrm{J}}\right)\left(\frac{\mu_{1}}{\mu_{2}-\mu_{1}}\right)^{\mathrm{r}} \frac{1-\mathrm{e}^{-\mathrm{J} \mu_{2}+(\mathrm{r}-\mathrm{J}) \mu_{\mu_{1}} \mathrm{t}}}{J_{\mu_{2}}+(\mathrm{r}-\mathrm{J}) \mu_{1}}\right]$

The mean number of packets in the second buffer is

$\mathrm{L}_{2}=\frac{\lambda \mathrm{a}+\mathrm{b}}{2 \mu_{2}}\left[1-\mathrm{e}^{-\mu_{2} \mathrm{t}}+\frac{\mu_{2}}{\mu_{2}-\mu_{1}} \mathrm{e}^{-\mu_{2} \mathrm{t}}-\mathrm{e}^{-\mu_{1} \mathrm{t}}\right]$

The utilization of the second node is

$\mathrm{U}_{2}=1-\exp \left[\lambda \sum_{\mathrm{k}=\mathrm{a}=1}^{\mathrm{b}} \sum_{\mathrm{r}=1}^{\mathrm{k}} \sum_{\mathrm{J}=0}^{\mathrm{r}}-1^{3 \mathrm{r}-\mathrm{J}}\left(\frac{1}{\mathrm{~b}-\mathrm{a}+1}\right)\left({ }^{\mathrm{k}} \mathrm{C}_{\mathrm{r}}\right)\left({ }^{\mathrm{T}} \mathrm{C}_{\mathrm{J}}\right)\left(\frac{\mu_{1}}{\mu_{2}-\mu_{1}}\right)^{\mathrm{r}} \frac{1-\mathrm{e}^{-\mathrm{J} \mu_{2}+(\mathrm{r}-\mathrm{J}) \mu_{1} \mathrm{t}}}{\mathrm{J} \mu_{2}+(\mathrm{r}-\mathrm{J}) \mu_{1}}\right]$

The mean number of packets in the network is

$\mathrm{L}_{\mathrm{N}}=\mathrm{L}_{1}+\mathrm{L}_{2}$

Throughput of the first node is

$\mathrm{Thp}_{1}=\mu_{1}\left[1-\exp \left[\lambda \sum_{\mathrm{k}=\mathrm{a}=1}^{\mathrm{b}} \sum_{\mathrm{r}=1}^{\mathrm{k}}\left(\frac{1}{\mathrm{~b}-\mathrm{a}+1}\right)^{\mathrm{k}} \mathrm{C}_{\mathrm{r}}-1 \frac{3 \mathrm{r}}{\mathrm{r} \mu_{1}}\right]\right]$

The average delay in the first buffer is

$$
\mathrm{W} \mathrm{N}_{1}=\frac{\mathrm{L}_{1}}{\operatorname{Thp}_{1}}=\frac{\frac{\lambda(\mathrm{a}+\mathrm{b})}{2 \mu_{1}} 1-\mathrm{e}^{-\mu_{1} \mathrm{t}}}{\mu_{1}\left[1-\exp \left[\lambda \sum_{\mathrm{k}=\mathrm{a}=1}^{\mathrm{b}} \sum_{\mathrm{r}=1}^{\mathrm{k}}\left(\frac{1}{\mathrm{~b}-\mathrm{a}+1}\right)^{\mathrm{k}} \mathrm{C}_{\mathrm{r}}-1{ }^{3 \mathrm{r}} \frac{1-\mathrm{e}^{-\mathrm{r} \mu_{1} \mathrm{t}}}{\mathrm{r} \mu_{1}}\right]\right]}
$$

Throughput of the second node is

$$
\operatorname{Thp}_{2}=\mu_{2}\left[1-\exp \left[\lambda \sum_{k=a}^{b} \sum_{r=1}^{k} \sum_{J=0}^{r}-1^{3 r-J}\left(\frac{1}{b-a+1}\right)\left({ }^{k} C_{r}\right)\left({ }^{r} C_{J}\right)\left(\frac{\mu_{1}}{\mu_{2}-\mu_{1}}\right)^{r} \frac{1-e^{-J \mu_{2}+(r-5) \mu_{1} t}}{J \mu_{2}+(r-J) \mu_{1}}\right]\right]
$$

The average delay in the second buffer is

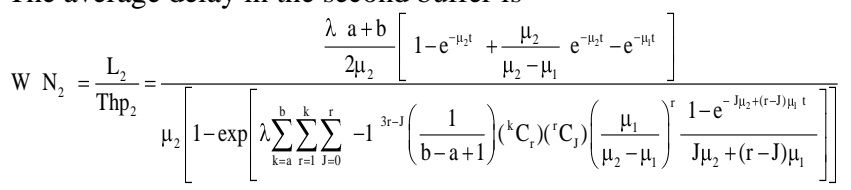

The variance of the number of packets in the first buffer is

$\operatorname{Var} \mathrm{N}_{1}=\mathrm{E}\left[\mathrm{N}_{1}^{2}-\mathrm{N}_{1}\right]+\mathrm{E} \mathrm{N}_{1}-\mathrm{E} \mathrm{N}_{1}^{2}$

$=\lambda\left[\sum_{\mathrm{k}=\mathrm{a}}^{\mathrm{b}}\left(\frac{1}{\mathrm{~b}-\mathrm{a}+1}\right) \mathrm{k}(\mathrm{k}-1)\left(\frac{1-\mathrm{e}^{-2 \mu_{\mathrm{l}} \mathrm{t}}}{2 \mu_{1}}\right)+\sum_{\mathrm{k}=\mathrm{a}}^{\mathrm{b}}\left(\frac{1}{\mathrm{~b}-\mathrm{a}+1}\right) \mathrm{k}\left(\frac{1-\mathrm{e}^{-\mu_{1} \mathrm{t}}}{\mu_{1}}\right)\right]$

The variance of number of packets in the second buffer is

$\operatorname{Var} \mathrm{N}_{2}=\mathrm{E}\left[\mathrm{N}_{2}^{2}-\mathrm{N}_{2}\right]+\mathrm{E} \mathrm{N}_{2}-\mathrm{E} \mathrm{N}_{2}$

$$
\begin{array}{r}
=\left\{\left(\sum_{k=1}^{\infty} \frac{1}{\mathrm{~b}+\mathrm{a}-1} \cdot \mathrm{k}(\mathrm{k}-1)\right)\left(\frac{\mu_{1}}{\mu_{1}-\mu_{2}}\right)^{2}\left[\left(\frac{1-\mathrm{e}^{-2 \mu_{1} \mathrm{t}}}{2 \mu_{1}}\right)-2\left(\frac{1-\mathrm{e}^{-\left(\mu_{1}+\mu_{2}\right) \mathrm{t}}}{\mu_{1}+\mu_{2}}\right)+\left(\frac{1-\mathrm{e}^{-2 \mu_{2} \mathrm{t}}}{2 \mu_{2}}\right)\right]\right\} \\
+\left\{\lambda \sum_{\mathrm{k}=1}^{\infty} \mathrm{k} \cdot \frac{1}{\mathrm{~b}+\mathrm{a}-1}\left[\left(\frac{1-\mathrm{e}^{-\mu_{2} \mathrm{t}}}{\mu_{2}}\right)-\left(\frac{\mathrm{e}^{-\mu_{2} \mathrm{t}}-\mathrm{e}^{-\mu_{1} \mathrm{t}}}{\mu_{1}-\mu_{2}}\right)\right]\right\}
\end{array}
$$

The coefficient of variation of the number of packets in the first buffer is

$$
\operatorname{cv} \mathrm{N}_{1}=\frac{\sqrt{\mathrm{Var} \mathrm{N}_{1}}}{\mathrm{~L}_{1}}
$$

The coefficient of variation of the number of packets in the second buffer is

$$
\text { cV } \mathrm{N}_{2}=\frac{\sqrt{\mathrm{V} \text { ar } \mathrm{N}_{2}}}{\mathrm{~L}_{2}}
$$

\section{PERFORMANCE EVALUATION OF THE COMMUNICATION NETWORK}

The performance of the proposed network is discussed through numerical data illustration. Different values of the parameters are considered for bandwidth allocation and arrival of packets. After interacting with the technical staff at the Internet service providing station, it is considered that the message arrival rate $(\lambda)$ varies from $1 \times 10^{4}$ messages $/ \mathrm{sec}$ to $5 \times 10^{4}$ messages $/ \mathrm{sec}$. Then each message is converted into some number of packets of arbitrary size depending on the size of the message. It is assumed that the number of packets that a message can be converted into varies from 1 to 30 . Hence, the number of arrivals of packets to the buffer are in batches of

random size. The batch size is assumed to follow uniform distribution with parameters $(\mathrm{a}, \mathrm{b})$. After node 1 , the packets are forwarded to the connected buffers at the node 2 , with a forward transmission rate $\left(\mu_{1}\right)$ of $2.5 \times 10^{4}$ packets/sec to $4.5 \times 10^{4}$ packets/sec. It is further assumed that the packets leave the second node with a transmission rate $\left(\mu_{2}\right)$ of $5 \times 10^{4}$ packets/sec to $9 \times 10^{4}$ packets/sec. In both the nodes, dynamic bandwidth allocation is considered i.e. the transmission rate of each packet depends on the number of packets in the buffer connected to it at that instant.

From the equations (37), (38),(41), (42) and (43) the mean number of packets and the utilization of the network are computed for different values of $t, a, b, \lambda, \mu_{1}, \mu_{2}$ and are given in Table1. 
Table 1. Values of mean, average delay, throughput and utilization of the network model

\begin{tabular}{|c|c|c|c|c|c|c|c|c|c|c|c|c|c|c|}
\hline$t^{*}$ & $\mathbf{a}$ & b & $\lambda^{\#}$ & $\mu_{1}{ }^{\$}$ & $\boldsymbol{\mu}_{2}{ }^{\$}$ & $\mathbf{L}_{1}$ & $\mathrm{U}_{1}$ & $\mathbf{L}_{2}$ & $\mathbf{U}_{2}$ & $\mathbf{L}_{\mathbf{N}}$ & Thp1 & Thp2 & W(N1) & W(N2) \\
\hline 0.1 & 5 & 25 & 2 & 4 & 8 & 2.47260 & 0.18126 & 0.40758 & 0.31326 & 2.88018 & 0.99568 & 0.76957 & 0.74500 & 0.16378 \\
\hline 0.3 & 5 & 25 & 2 & 4 & 8 & 5.24104 & 0.44942 & 1.83124 & 0.80657 & 7.07228 & 2.10044 & 2.88004 & 0.74856 & 0.20557 \\
\hline 0.5 & 5 & 25 & 2 & 4 & 8 & 6.48499 & 0.61864 & 2.80364 & 0.92103 & 9.28865 & 2.56651 & 3.97978 & 0.75803 & 0.23405 \\
\hline 0.9 & 5 & 25 & 2 & 4 & 8 & 7.19428 & 0.74146 & 3.45051 & 0.95760 & 10.6448 & 2.81402 & 4.59534 & 0.76697 & 0.25455 \\
\hline 1.0 & 5 & 25 & 2 & 4 & 8 & 7.36263 & 0.77384 & 3.61389 & 0.96391 & 10.97652 & 2.87024 & 4.73880 & 0.76955 & 0.26005 \\
\hline 1 & 1 & 25 & 2 & 4 & 8 & 6.38095 & 0.74675 & 3.13204 & 0.94384 & 9.51299 & 2.98701 & 7.55072 & 2.13623 & 0.41480 \\
\hline 1 & 2 & 25 & 2 & 4 & 8 & 6.62638 & 0.75590 & 3.25250 & 0.94969 & 9.87887 & 3.02359 & 7.59749 & 2.19156 & 0.42810 \\
\hline 1 & 3 & 25 & 2 & 4 & 8 & 6.87179 & 0.76299 & 3.37296 & 0.95497 & 10.24476 & 3.05197 & 7.63972 & 2.25159 & 0.44150 \\
\hline 1 & 4 & 25 & 2 & 4 & 8 & 7.11721 & 0.76885 & 3.49343 & 0.95969 & 10.61064 & 3.07538 & 7.67748 & 2.31425 & 0.45502 \\
\hline 1 & 5 & 25 & 2 & 4 & 8 & 7.36263 & 0.77384 & 3.61389 & 0.96391 & 10.97652 & 3.09538 & 7.71129 & 2.37859 & 0.46865 \\
\hline 1 & 5 & 10 & 2 & 4 & 8 & 3.68132 & 0.71357 & 1.80695 & 0.81003 & 5.48826 & 2.85428 & 6.48023 & 1.28975 & 0.27884 \\
\hline 1 & 5 & 15 & 2 & 4 & 8 & 4.90842 & 0.74134 & 2.40926 & 0.89079 & 7.31768 & 2.96534 & 7.12635 & 1.65526 & 0.33808 \\
\hline 1 & 5 & 20 & 2 & 4 & 8 & 6.13553 & 0.76011 & 3.01158 & 0.93722 & 9.14710 & 3.04044 & 7.49777 & 2.01797 & 0.40166 \\
\hline 1 & 5 & 25 & 2 & 4 & 8 & 7.36263 & 0.77384 & 3.61389 & 0.96391 & 10.97652 & 3.09538 & 7.71129 & 2.37859 & 0.46865 \\
\hline 1 & 5 & 30 & 2 & 4 & 8 & 8.58974 & 0.78441 & 4.21621 & 0.97925 & 12.80594 & 3.13762 & 7.83403 & 2.73766 & 0.53819 \\
\hline 1 & 5 & 25 & 1.0 & 4 & 8 & 3.68132 & 0.52444 & 1.80695 & 0.81003 & 5.48826 & 2.09777 & 6.48023 & 1.75487 & 0.27884 \\
\hline 1 & 5 & 25 & 1.5 & 4 & 8 & 5.52197 & 0.67205 & 2.71042 & 0.91720 & 8.23239 & 2.68821 & 7.33760 & 2.05415 & 0.36939 \\
\hline 1 & 5 & 25 & 2.0 & 4 & 8 & 7.36263 & 0.77384 & 3.61389 & 0.96391 & 10.97652 & 3.09538 & 7.71129 & 2.37859 & 0.46865 \\
\hline 1 & 5 & 25 & 2.5 & 4 & 8 & 9.20329 & 0.84404 & 4.51736 & 0.98427 & 13.72065 & 3.37617 & 7.87416 & 2.72596 & 0.57369 \\
\hline 1 & 5 & 25 & 3.0 & 4 & 8 & 11.04395 & 0.89245 & 5.42084 & 0.99314 & 16.46479 & 3.56980 & 7.94515 & 3.09372 & 0.68228 \\
\hline 1 & 5 & 25 & 2 & 2.5 & 8 & 11.01498 & 0.84248 & 3.30284 & 0.95469 & 14.31782 & 2.10620 & 7.63750 & 5.22978 & 0.43245 \\
\hline 1 & 5 & 25 & 2 & 3.0 & 8 & 9.50213 & 0.82442 & 3.45203 & 0.95973 & 12.95416 & 2.47325 & 7.67781 & 3.84195 & 0.44961 \\
\hline 1 & 5 & 25 & 2 & 3.5 & 8 & 8.31259 & 0.80106 & 3.54966 & 0.96245 & 11.86226 & 2.80371 & 7.69961 & 2.96485 & 0.46102 \\
\hline 1 & 5 & 25 & 2 & 4.0 & 8 & 7.36263 & 0.77384 & 3.61389 & 0.96391 & 10.97652 & 3.09538 & 7.71129 & 2.37859 & 0.46865 \\
\hline 1 & 5 & 25 & 2 & 4.5 & 8 & 6.59261 & 0.74438 & 3.65640 & 0.96464 & 10.24900 & 3.34971 & 7.71710 & 1.98811 & 0.47380 \\
\hline 1 & 5 & 25 & 2 & 4 & 5 & 7.36263 & 0.77384 & 5.61224 & 0.99329 & 12.97487 & 3.09538 & 4.96647 & 2.37859 & 1.13003 \\
\hline 1 & 5 & 25 & 2 & 4 & 6 & 7.36263 & 0.77384 & 4.75005 & 0.98629 & 12.11269 & 3.09538 & 5.91771 & 2.37859 & 0.80268 \\
\hline 1 & 5 & 25 & 2 & 4 & 7 & 7.36263 & 0.77384 & 4.10777 & 0.97638 & 11.47040 & 3.09538 & 6.83469 & 2.37859 & 0.60102 \\
\hline 1 & 5 & 25 & 2 & 4 & 8 & 7.36263 & 0.77384 & 3.61389 & 0.96391 & 10.97652 & 3.09538 & 7.71129 & 2.37859 & 0.46865 \\
\hline 1 & 5 & 25 & 2 & 4 & 9 & 7.36263 & 0.77384 & 3.22377 & 0.94935 & 10.58640 & 3.09538 & 8.54416 & 2.37859 & 0.37731 \\
\hline
\end{tabular}

The relationship between mean number of packets in the buffers and in the whole network and the utilization of the nodes with respect to the input parameters is shown in Figure 2.

It is observed that after 0.1 seconds, the first buffer is having on an average of 24726 packets, after 0.3 seconds it rapidly raised to an average of 52410.4 packets. After 1 second, the first buffer is containing an average of 73626.3 packets and there after the system stabilizes and the average number of packets remains to be the same for fixed values of other parameters $(5,25,2,4,8)$ for $(a, b$, $\left.\lambda, \mu_{1}, \mu_{2}\right)$. It is also observed that as time ( $\mathrm{t}$ ) varies from 0.1 to 1

seconds, average content of the second buffer and the network increase from 4075.8 packets to 36138.9 packets and from 28801.8 packets to 109765.2 packets respectively.

As the batch size distribution parameter (a) varies from $1 \times 10^{4}$ packets $/ \mathrm{sec}$ to $5 \times 10^{4}$ packets/sec, the first buffer, second buffer and the network average content increase from 63809.5 packets to 73626.3 packets, 31320.4 packets to 36138.9 packets and 95129.9 packets to 109765.2 packets respectively when other parameters remain fixed. As the batch size distribution parameter (b) varies from $10 \times 10^{4}$ packets/sec to $30 \times 10^{4}$ packets/sec, the first buffer, second buffer and the network average content increase from 36813.2 packets to 85897.4 packets, 18069.5 packets to 42162.1 packets and 54882.6 packets to 128059.4 packets respectively when other parameters remain fixed. As the arrival rate of messages $(\lambda)$ varies from $1 \times 10^{4}$ messages $/ \mathrm{sec}$ to $3 \times 10^{4}$ messages/sec, the first buffer, second buffer and the network average content increase from 36813.2 packets to 110439.5 packets, 18069.5 packets to 54208.4 packets and 54882.6 packets to 164647.9 packets respectively when other parameters remain fixed at $(1,5,25,4,8)$ for $\left(\mathrm{t}, \mathrm{a}, \mathrm{b}, \mu_{1}, \mu_{2}\right)$.
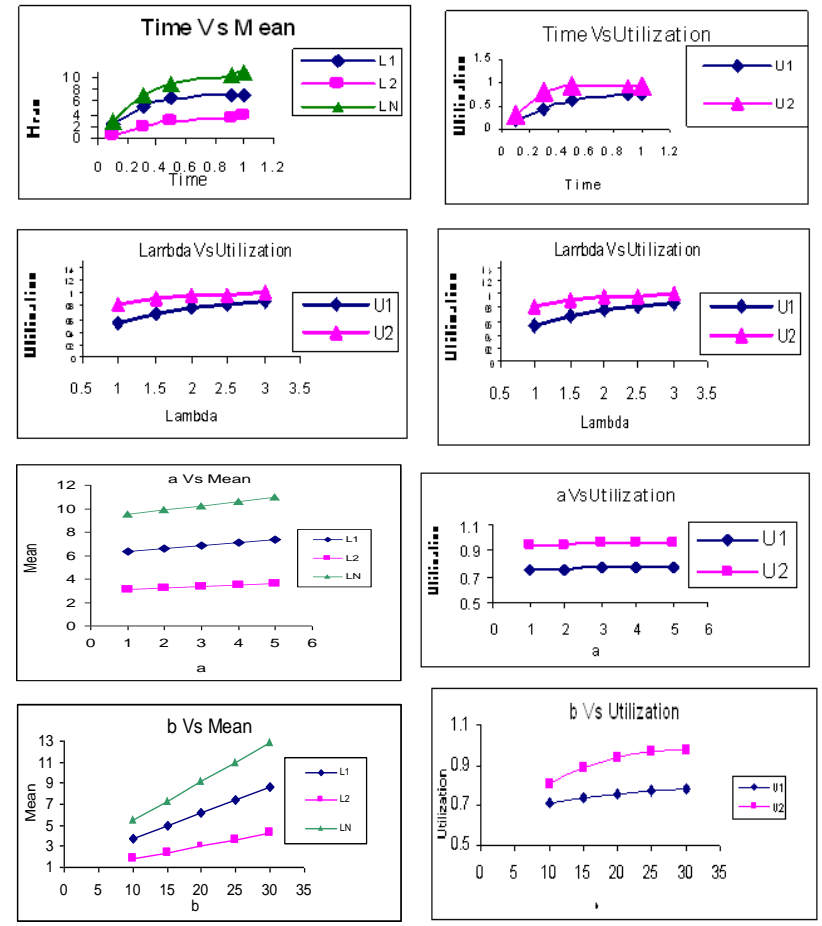

Fig 2. Relationship between Mean, Utilization and input parameters 

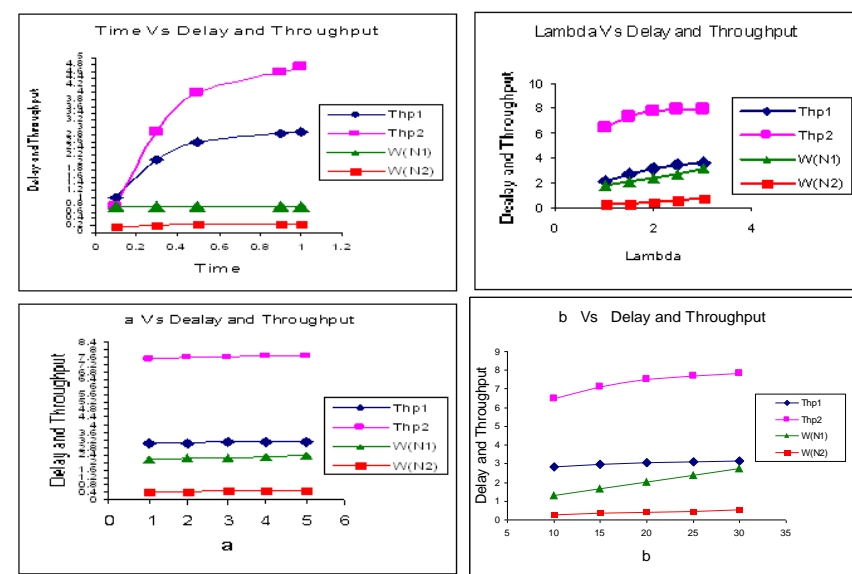

Fig 3. Relationship between Delay, Throughput and some input parameters

Similarly when the values of $\mathrm{t}, \lambda$, a, and $\mathrm{b}$ increases, the utilization of node 1 and node 2 were also increasing. The effect of variation in the transmission rates of the nodes $\left(\mu_{1}, \mu_{2}\right)$ on the mean number of packets in the buffers and network as well on utilization of the nodes can be observed from the table1.

From the equations (44) to (47), the throughput and the average delay of the network are computed for different values of $t, a, b, \lambda$, $\mu_{1}, \mu_{2}$ and are given in Table 1 . The relationship between average delay and throughput of the nodes with respect to the input parameters is in figure 3 . It can be observed from the table 1 and figure 3 that when the input parameters $t, \lambda, a, b$ are increasing, the throughput of the nodes and average delay in both the buffers are also increasing. The influence of the transmission rates of the nodes on the performance measures can also be observed from the table1.

The values of other performance measures like the probability of emptiness of the first, second buffers and the network are also computed and analyzed. When the values of the parameters $t, a, b$ and $\lambda$ increase, the probabilities of emptiness of both buffers decrease. When the transmission rate of node1 $\left(\mu_{1}\right)$ increases, the probability of emptiness of the first buffer increase whereas the probability of emptiness of the second buffer decreases. When the transmission rate of second node $\left(\mu_{2}\right)$ increases, the probability of emptiness of the second node increases whereas it remains constant for node1.

Using the equations given section 4, the values for variance of number of packets in each buffer and the coefficient of variation of the number of packets in each buffer are also computed. If the variance increases then the burstness of the buffers will be high. Hence, the parameters are to be adjusted such that the variance of the buffer content in each buffer must be small. The coefficient of variation of the number of packets in each buffer will helps us to understand the consistency of the traffic flow through buffers. If coefficient of variation is large then the flow is inconsistent and the requirement to search the assignable causes of high variation. It also helps us to compare the smooth flow of packets in two or more nodes.

From this analysis it is observed that the dynamic bandwidth allocation strategy has a significant influence on all performance measures of the network. It is further observed that the performance measures are highly sensitive towards smaller values of time. Hence, it is optimal to consider dynamic bandwidth allocation and evaluate the performance under transient conditions. It is also to be observed that the congestion in buffers and delays in transmission can be reduced to a minimum level by adapting dynamic bandwidth allocation. This phenomenon has a vital bearing on quality of service (QoS).

\section{SENSITIVITY ANALYSIS}

Sensitivity analysis of the model is performed with respect of the $t$, $a, b, \lambda, \mu_{1}, \mu_{2}$ on the mean number packets in the first and second buffers, the mean number of packets in the network, the mean delay in the first and second buffers, the utilization and throughput of the first and second nodes.

The following data has been considered for the sensitivity analysis. $\mathrm{t}=0.1 \mathrm{sec}, \mathrm{a}=5 \times 10^{4}$ packets $/ \mathrm{sec}, \mathrm{b}=25 \times 10^{4}$ packets $/ \mathrm{sec}, \lambda=$ $2 \times 10^{4}$ packets $/ \mathrm{sec}, \mu_{1}=4 \times 10^{4}$ packets $/ \mathrm{sec}, \mu_{2}=8 \times 10^{4}$ packets $/ \mathrm{sec}$

The performance measures of the model are computed with variation of $-15 \%,-10 \%, 0 \%,+5 \%,+10 \%$ and $+15 \%$ on the input parameters t, $\lambda, \mu_{1}, \mu_{2}$ and $-60 \%,-40 \%,-20 \%, 0 \%,+20 \%,+40 \%$ and $+60 \%$ on the batch size distribution parameters a and $b$ to retain them as integers. The computed values are given in Table 2.

The performance measures are highly affected by time (t) and the batch size distribution of arrivals. As (t) increases to $15 \%$ the average number of packets in the two buffers and total network increase along with the average delays in buffers. Similarly, as arrival rate of messages $(\lambda)$ increases by $15 \%$ the average number

Table 2. Sensitivity Analysis

\begin{tabular}{|c|c|c|c|c|c|c|c|c|}
\hline \multirow[t]{2}{*}{ Parameter } & \multirow{2}{*}{$\begin{array}{c}\text { Perform } \\
\text { ance } \\
\text { Measure } \\
\text { s }\end{array}$} & \multicolumn{7}{|c|}{$\%$ Change in Parameters } \\
\hline & & -15 & -10 & -5 & 0 & +5 & +10 & +15 \\
\hline \multirow{8}{*}{$t(=0.1)$} & $L_{1}$ & 2.16172 & 2.26743 & 2.37104 & 2.47260 & 2.57215 & 2.66973 & 2.76537 \\
\hline & $L_{2}$ & 0.31154 & 0.34274 & 0.37479 & 0.40758 & 0.44106 & 0.47516 & 0.50982 \\
\hline & $U_{1}$ & 0.15633 & 0.16473 & 0.17303 & 0.18126 & 0.18941 & 0.19747 & 0.20545 \\
\hline & $U_{2}$ & 0.25122 & 0.27202 & 0.29272 & 0.31326 & 0.33355 & 0.35357 & 0.37327 \\
\hline & $\operatorname{Thp}_{1}$ & 0.87001 & 0.91274 & 0.95463 & 0.99568 & 1.03593 & 1.07537 & 1.11403 \\
\hline & $\operatorname{Thp}_{2}$ & 0.59802 & 0.65431 & 0.71155 & 0.76957 & 0.82824 & 0.88743 & 0.94702 \\
\hline & $W\left(N_{I}\right)$ & 0.74541 & 0.74526 & 0.74512 & 0.74500 & 0.74488 & 0.74478 & 0.74470 \\
\hline & $W\left(N_{2}\right)$ & 0.16043 & 0.16154 & 0.16266 & 0.16378 & 0.16491 & 0.16603 & 0.16716 \\
\hline \multirow{6}{*}{$\lambda(=2)$} & $L_{I}$ & 6.25824 & 6.62637 & 6.99450 & 7.36263 & 7.73076 & 8.09890 & 8.46703 \\
\hline & $L_{2}$ & 3.07181 & 3.25250 & 3.4332 & 3.61389 & 3.79459 & 3.97528 & 4.15597 \\
\hline & $U_{1}$ & 0.71735 & 0.73760 & 0.75639 & 0.77384 & 0.79004 & 0.80508 & 0.81905 \\
\hline & $U_{2}$ & 0.94060 & 0.94969 & 0.95739 & 0.96391 & 0.96943 & 0.97411 & 0.97807 \\
\hline & $T h p_{1}$ & 2.86941 & 2.95039 & 3.02558 & 3.09538 & 3.16018 & 3.22034 & 3.27618 \\
\hline & $T h p_{2}$ & 7.52482 & 7.59794 & 7.65912 & 7.71129 & 7.75547 & 7.79289 & 7.82458 \\
\hline
\end{tabular}




\begin{tabular}{|c|c|c|c|c|c|c|c|c|}
\hline & $W\left(N_{1}\right)$ & 2.18102 & 2.24593 & 2.31179 & 2.37859 & 2.44631 & 2.51492 & 2.58442 \\
\hline & $W\left(N_{2}\right)$ & 0.40822 & 0.42810 & 0.44825 & 0.46865 & 0.48928 & 0.51012 & 0.53114 \\
\hline \multirow{8}{*}{$\mu_{1}(=4)$} & $L_{1}$ & 8.52906 & 8.10564 & 7.71813 & 7.36263 & 7.03575 & 6.73447 & 6.45618 \\
\hline & $L_{2}$ & 3.53328 & 3.56473 & 3.59135 & 3.61389 & 3.63300 & 3.64923 & 3.66301 \\
\hline & $U_{1}$ & 0.80609 & 0.79587 & 0.78509 & 0.77384 & 0.76224 & 0.75038 & 0.73835 \\
\hline & $U_{2}$ & 0.96203 & 0.96282 & 0.96344 & 0.96391 & 0.96427 & 0.96453 & 0.96472 \\
\hline & $T h p_{1}$ & 2.74072 & 2.86515 & 2.98334 & 3.09538 & 3.20142 & 3.30168 & 3.39640 \\
\hline & $T h p_{2}$ & 7.69625 & 7.70258 & 7.70750 & 7.71129 & 7.71416 & 7.71628 & 7071779 \\
\hline & $W\left(N_{1}\right)$ & 3.11198 & 2.82905 & 2.58707 & 2.37859 & 2.19770 & 2.03971 & 1.90089 \\
\hline & $W\left(N_{2}\right)$ & 0.45909 & 0.46280 & 0.46595 & 0.46865 & 0.47095 & 0.47293 & 0.47462 \\
\hline \multirow{8}{*}{$\mu_{2}(=8)$} & $L_{1}$ & 7.36263 & 7.36263 & 7.36263 & 7.36263 & 7.36263 & 7.36263 & 7.36263 \\
\hline & $L_{2}$ & 4.22255 & 3.99885 & 3.79693 & 3.61389 & 3.44728 & 3.29505 & 3.15546 \\
\hline & $U_{I}$ & 0.77384 & 0.77384 & 0.77384 & 0.77384 & 0.77384 & 0.77384 & 0.77384 \\
\hline & $U_{2}$ & 0.97858 & 0.97408 & 0.96918 & 0.96391 & 0.95831 & 0.95241 & 0.94263 \\
\hline & $T h p_{1}$ & 3.09538 & 3.09538 & 3.09538 & 3.09538 & 3.09538 & 3.09538 & 3.09538 \\
\hline & $T h p_{2}$ & 6.65437 & 7.01338 & 7.36576 & 7.71129 & 8.04979 & 8.38117 & 8.70536 \\
\hline & $W\left(N_{1}\right)$ & 2.37859 & 2.37859 & 2.37859 & 2.37859 & 2.37859 & 2.37859 & 2.37859 \\
\hline & $W\left(N_{2}\right)$ & 0.63455 & 0.57017 & 0.51548 & 0.46865 & 0.42824 & 0.39315 & 0.36247 \\
\hline & & $-60 \%$ & $-40 \%$ & $-20 \%$ & $0 \%$ & $+20 \%$ & $+40 \%$ & $+60 \%$ \\
\hline \multirow{8}{*}{$a(=5)$} & $L_{1}$ & 6.62637 & 6.87179 & 7.11721 & 7.36263 & 7.60805 & 7.85347 & 8.09890 \\
\hline & $L_{2}$ & 3.25250 & 3.37296 & 3.49343 & 3.61389 & 3.73435 & 3.85482 & 3.97528 \\
\hline & $U_{1}$ & 0.75590 & 0.76299 & 0.76885 & 0.77384 & 0.77821 & 0.78208 & 0.78556 \\
\hline & $U_{2}$ & 0.94969 & 0.95497 & 0.95969 & 0.96391 & 0.96769 & 0.97108 & 0.97411 \\
\hline & $T h p_{1}$ & 3.02359 & 3.05197 & 3.07538 & 3.09538 & 3.11284 & 3.12833 & 3.14224 \\
\hline & $T h p_{2}$ & 7.59749 & 7.63972 & 7.67748 & 7.71129 & 7.74155 & 7.76864 & 7.79289 \\
\hline & $W\left(N_{1}\right)$ & 2.19156 & 2.25159 & 2.31425 & 2.37859 & 2.44409 & 2.51043 & 2.57742 \\
\hline & $W\left(N_{2}\right)$ & 0.42810 & 0.44150 & 0.45502 & 0.46865 & 0.48238 & 0.49620 & 0.51012 \\
\hline \multirow{8}{*}{$b(=25)$} & $L_{1}$ & 3.68132 & 4.90842 & 6.13553 & 7.36263 & 8.58974 & 7.81684 & 11.04395 \\
\hline & $L_{2}$ & 1.80695 & 2.40926 & 3.01158 & 3.61389 & 4.21621 & 4.81852 & 5.42084 \\
\hline & $U_{1}$ & 0.71357 & 0.74134 & 0.76011 & 0.77384 & 0.78441 & 0.79282 & 0.79969 \\
\hline & $U_{2}$ & 0.81003 & 0.89079 & 0.93722 & 0.96391 & 0.97925 & 0.98807 & 0.99314 \\
\hline & $T h p_{1}$ & 2.85428 & 2.96534 & 3.04044 & 3.09538 & 3.13762 & 3.17126 & 3.19874 \\
\hline & $T h p_{2}$ & 6.48023 & 7.12635 & 7.49777 & 7.71129 & 7.83403 & 7.90459 & 7.94511 \\
\hline & $W\left(N_{1}\right)$ & 1.28925 & 1.65526 & 2.01797 & 2.37859 & 2.73766 & 3.09557 & 3.45259 \\
\hline & $W\left(N_{2}\right)$ & 0.27884 & 0.33808 & 0.40166 & 0.46865 & 0.53819 & 0.60959 & 0.68228 \\
\hline
\end{tabular}


of packets in the two buffers and total network increases along with the average delays in buffers. The mean delays and mean content of the buffers are decreasing function of these parameters. Overall analysis of the parameters reflects that dynamic bandwidth allocation strategy for congestion control tremendously reduces the delays in communication and improves quality of service (QoS) by reducing burstness in buffers.

\section{CONCLUSIONS}

In this paper a two node Communication network with dynamic bandwidth allocation having bulk arrivals is developed and analyzed under transient condition. The dynamic bandwidth allocation strategy here reflects the instantaneous changing rate of transmission in nodes depending upon the content of the buffer connected to it. The novelty of this Communication network is that the arrival of packets to the initial node is in bulk with random size. The performance of the statistical multiplexing is measured by approximating the arrival process with a compound Poisson and the transmission process with Poisson process. This is chosen such that the statistical characteristics of the Communication network identically match with the Poisson process and uniform distribution. The sensitivity of the network with respect to input parameters is studied through numerical illustrations. It is observed that the dynamic bandwidth allocation strategy and the parameters of bulk size distribution have a significant impact on the performance measures of the network. It is further observed that transient analysis of the Communication network will approximate the performance measures more close to the practical situation. This network can also be extended to the multi node communication networks. It is interesting to note that this Communication network model includes some of the earlier Communication network model given by P.S.Varma and K.Srinivasa Rao (2007)

\section{REFERENCES}

[1]. Kleinrock. L (1976), Queuing systems, Vol-II: Computer Applications, Wiley publications, New York

[2]. Martin Reiser (1982), Performance evaluation of Data Communication systems, proceedings of the IEEE, vol.70, No.2, pp 171-196.

[3]. Jaime Jungok Bae and tatsuya Suda (1991), Survey of traffic control systems and protocols in ATM networks, proceedings of the IEEE, vol.79, No.2, pp 170-189.

[4]. Yukuo Hayashida (1993), Throughput analysis of tandem type go-back NARQ scheme for satellite communications, IEEE Transactions on Communications, Vol.41, pp 1517-1524

[5]. Kin K. Leung (2002), Load dependent service queues with application to congestion control in broadband networks, Performance Evaluation, Vol.50, Issue 14, pp 27-40.

[6]. Paul Dupis, Kevin Leder and HuiWang (2007), Large deviation and importance sampling for a tandem network with slow-down, Queuing systems, Vol.57, pp 71-83.

[7]. P.Suresh Varma and K.Srinivasa Rao (2007), A Communication network with load dependent transmission, International Journal of Matnemetical Sciences, Vol.6, No.2, pp.199-210.

[8]. Emre Yetginer and Ezhan Karasan (2008), Dynamic wavelength allocation in IP/WDM metro access networks, IEEE Journal on selected areas in Communications, Vol.26, No.3, pp 13-27.

[9]. Gunadle, A.S and Yadri, A.R (2008), Performance evaluation of issues related to video over broadband networks, Proceedings of World Academy of Sciences, Engineering and technology, Vol.36, pp 122-125

[10]. Hongwang Yu and yufan Zheng (2009), Global behavior of dynamical agents in direct network, Journal of control theory and applications, Vol.7, No.3, pp 307-314.

[11]. Fen Zhou, Miklos Molnar and Bernard Cousin (2009), Avoidance of multicast incapable branching nodes for multicast routing in WDM, Photonic network communications, Vol.18, No.3, pp378-392.

[12]. Stanislav Angelov, Sanjeev Khanna and Keshav Kunal (2009), The network as a storage device:Dynamic routing with bounded buffers, Algorithmica, Vol.55, No.1, pp 7194.

\section{AUTHORS PROFILE}

Dr. Peri. Srinivasa Rao is presently working as Professor in the Department of Computer Science and Systems Engineering, Andhra University, Visakhapatnam. He got his Ph.D degree from Indian Institute of Technology, Kharagpur in Computer Science in 1987. He published several research papers and delivered invited lectures at various conferences, seminars and workshops. He guided a large number of students for their M.Tech degrees in Computer Science and Engineering and Information Technology. His current research interests are Communication networks, Data Mining and Computer Morphology

Dr. Kuda Nageswara Rao is presently working as Associate professor in the Department of Computer Science and Systems Engineering, Andhra University, Visakhapatnam. He presented several research papers in national and International conferences and seminars. He published a good number of papers in national and International journals. He guided several students for getting their M.Tech degrees in Computer Science and Engineering. His current research interests are Communication networks, Internet Technologies and Network security.

Dr. K.Srinivasa Rao is presently working as Professor and head, Department of Statistics, Andhra University, Visakhapatnam. He is elected chief editor of Journal of ISPS and elected VicePresident of Operation Research of India. He guided 22 students for Ph.D in Statistics, Computer Science, Electronics and Communications and Operations Research. He published 75 research papers in national and International journals with high reputation. His research interests are Communication Systems, Data Mining and stochastic models. 